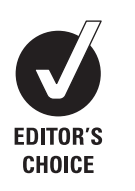

CHOICE

- Additional data are published online only. To view these files, please visit the journal online (http://ard.bmj.com/ content/71/7.toc).

For numbered affiliations see end of article

\section{Correspondence to}

Jean-Marie Berthelot, Service de Rhumatologie, Hotel-Dieu, Centre Hospitalo-Universitaire de Nantes, Nantes F-44000,

France;

jeanmarie.berthelot@

chu-nantes.fr

$\mathrm{JMB}$ and MDB contributed equally to this study.

Received 20 January 2011 Accepted 6 October 2011 Published Online First 9 November 2011

\title{
A tool to identify recent or present rheumatoid arthritis flare from both patient and physician perspectives: The 'FLARE' instrument
}

\author{
Jean-Marie Berthelot, ${ }^{1}$ Michel De Bandt, ${ }^{2}$ Jacques Morel, ${ }^{3}$ Fatima Benatig, 4,5,6 \\ Arnaud Constantin, 7,8 Philippe Gaudin, ${ }^{9}$ Xavier Le Loet, ${ }^{10}$ Jean-Francis Maillefert, ${ }^{11}$ \\ Olivier Meyer, ${ }^{12,13,14}$ Thao Pham, ${ }^{15}$ Alain Saraux, ${ }^{16}$ Elisabeth Solau-Gervais, ${ }^{17}$ \\ Elisabeth Spitz, ${ }^{4,5,6}$ Daniel Wendling, ${ }^{18,19}$ Bruno Fautrel, ${ }^{13,20,21}$ Francis Guillemin, 4,5,6,22 \\ on behalf of the STPR group of the French Society of Rheumatology
}

\section{ABSTRACT \\ Introduction There is a lack of consensus about the definition of flare of rheumatoid arthritis (RA) and a measurement tool.}

Objectives To develop a self-administered tool integrating the perspectives of the patient and the rheumatologist, enabling the detection of present or recent-past RA flare.

Methods The patient perspective was explored by semistructured individual interviews of patients with RA. Two health psychologists conducted a content analysis to extract items best describing flare from the interviews. The physician's perspective was explored through a Delphi exercise conducted among a panel of 13 rheumatologists. A comprehensive list of items produced in the first round was reduced in a four-round Delphi process to select items cited by at least $75 \%$ of the respondents. The identified elements were assembled in domains - each converted into a statement- to constitute the final self-administered Flare Assessment in Rheumatoid Arthritis (FLARE) questionnaire.

Results The content of 99 patient interviews was analysed, and 10 domains were identified: joint swelling or pain, night pain, fatigue and different emotional consequences, as well as analgesic intake. The Delphi process for physicians identified eight domains related to objective RA symptoms and drug intake, of which only four were common to domains for patients. Finally, 13 domains were retained in the FLARE questionnaire, formulated as 13 statements with a Likert-scale response modality of six answers ranging from 'absolutely true' to 'completely untrue'.

Conclusion Two different methods, for patient and physician perspectives, were used to develop the FLARE self-administered questionnaire, which can identify past or present RA flare.

\section{INTRODUCTION}

Although the question of a consensual definition of rheumatoid arthritis (RA) flare has been raised previously, ${ }^{1-4}$ clinicians still lack a consensual definition for it, from either a conceptual or practical point of view. ${ }^{1-4}$ This lack of consensus is due in part to the ambiguity of the concept because of two possible approaches to the definition.
The first approach may represent an ongoing worsening in RA activity of sufficient duration to prompt a change in RA treatment. This approach has been preferred by the Outcome Measures in Rheumatology (OMERACT) Flare group, which sought mainly to describe clinically relevant worsening, first in randomised controlled trials (RCTs) incorporating the patient's perspective, to improve the ability to capture loss of efficacy as early as possible in RCTs and longitudinal observational and post-marketing studies, ${ }^{5}$ and ultimately in clinical practice. ${ }^{6}$ In a preliminary definition, flare was accordingly defined as 'a cluster of symptoms of sufficient duration and intensity that cannot be self-managed by the patient and require initiation, change or increase in therapy'. ${ }^{257}$ In this approach, flare is the opposite of improvement, keeping in mind that the intensity of change is not symmetrical between the two notions.

In the context of RCTs, visits are already scheduled and separated by quite short intervals, allowing adaptation of the treatment as soon as a significant 'flare' is prospectively detected. This definition of flare does not yet consider the possibility of transient exacerbation of disease activity with spontaneous return to baseline disease activity.

The second approach encompasses any disease exacerbation, either transient (ie, spontaneously regressive) or long lasting. Such a definition would be more suitable for all settings, either in clinical research or daily practice, for identifying present flare or exacerbation of RA activity that has occurred between two visits to the physician. Transient flares definitely occur during RA, and may have significant impact on disease outcome. Welsing et al showed that brief and marked fluctuations in disease activity in patients with apparently stable RA are directly related to radiographic evidence of disease progression, which suggests that, at the individual level, transient fluctuations can also induce variation in structural damage. ${ }^{8}$ This evidence may explain structural damage progression in patients with apparent remission at successive medical visits. Because fluctuations in disease activity are common in chronic inflammatory rheumatisms, ${ }^{9}$ there is definitely an unmet 
need to identify such transient flares because they would be predictive of future worse outcome and would justify treatment adaptation even in patients in stable remission at the time of the consultation.

Defining RA flare raises another complex issue related to the difference in perception or concept of flare between patients and health professionals. Physicians may focus more on objective signs, such as the clinical features observed during the medical visit, but fail to notice patient-reported events that occurred before the consultation. Patients may have a different concept, depending first on what they experience in daily life as a consequence of the disease and its activity. For instance, a previous study on flare in ankylosing spondylitis showed that, besides acute pain, many patients experienced reduced mobility, fatigue, depression, anger, fear and generalised whole-body reactions felt as a devastating phenomenon. ${ }^{10}$ Moreover, patients may disagree with physicians on the magnitude of disease activity worsening required to define a flare. Indeed, in a study by Leeb et al, in contrast with physicians' perspectives, patients required greater improvement to feel satisfied, and less worsening to feel dissatisfied. ${ }^{11}$ Defining a worsening of RA should clearly not depend on only physicians' perspectives. ${ }^{12}$

The Strategy of Treatment in Patients with Rheumatoid Arthritis (STPR) initiative, comprising a group of senior faculty rheumatologists, ${ }^{13-15}$ began a study in 2007 with the goal of developing a self-administered tool to capture RA flare according to the second approach described above: transient or long lasting, present or recent (ie, within the previous 3 months to limit recall bias), regardless of any clinical evaluation by the rheumatologist. In this work, we aimed, through creation of a questionnaire, to define the components constituting RA flare according to patient and physician perspectives, and to develop the domains able to identify and capture such a flare.

\section{METHODS}

The study involved developing two comprehensive lists of items that could define flare from a patient and/or a rheumatologist perspective with two qualitative methods: semistructured interviews to elicit patient views, and a Delphi exercise to reach consensus among physicians.

\section{Patient perspective}

Before the study, two health psychologists (FB, ES) performed a content analysis based on a non-structured discussion with 10 patients with RA and used their answers to develop the format of subsequent patient interviews that were planned in the main study (see online supplementary text).

Then, eight to ten consecutive patients with established RA (ie, more than 2 years' duration) included in each of the 13 participating rheumatology departments were asked to participate in individual semistructured interviews that explored their feelings and thoughts about RA flare. A research nurse or a health psychologist in each centre conducted 10-15 min interviews, which were recorded for further analysis. All patients received adequate information about the objectives and process of the study and gave their consent to participate before the interview.

\section{Content analysis}

The interviews were transcribed on to paper by the two health psychologists (FB, ES), and their content was analysed to identify the attributes patients used to describe RA flare and the frequency with which these elements were cited.
In the first step, the two health psychologists performed an explanatory thematic analysis based on a non-structured discussion with 10 patients, who were asked to describe their usual symptoms and feelings when a disease flare occurs, and 26 themes were initially developed. The eight most frequently reported were finally selected to develop the format of subsequent patient interviews. In the second step, this guide of eight main themes with open questions was an opportunity for 102 other patients to offer their opinions on flare. Over 350 pages, the patients described in detail what they experienced during an RA flare. Codes were developed for latent characteristics that can be reliably applied, and a coding frame was created that contains the label for each code, its definition, and examples of what should and should not be coded with it. To establish the reliability of the coding system, two people then independently used the manual to apply the codes. Finally, the identified attributes were reorganised into discrete domains, each representing a relevant RA flare feature.

\section{Physician perspective}

A panel of 13 senior university rheumatologists (all listed among the authors) experienced in the care of patients with RA participated in a Delphi exercise. The rheumatologists were first asked to list the elements that best reflected RA flares, introduced as transient exacerbations of disease activity. They were asked to respond to the following statement: 'By excluding the variations of disease activity due to an end-ofdose effect from a treatment such as biotherapy, please state the elements that you consider to best describe or represent a flare in an RA patient'. Each expert had to propose at least 10 items during the preliminary round. The proposed items were first organised into several domains and then reduced during a four-round Delphi process in which items were definitively selected when cited by at least $75 \%$ of the 13 participants and definitively rejected when cited by fewer than $25 \%$ of them. At each round, the remaining items were maintained for the following procedure.

\section{Elaboration of self-administered questionnaire and cognitive testing}

Both patient- and physician-reported domains were used to develop the Flare Assessment in Rheumatoid Arthritis (FLARE) self-administered questionnaire. During the final meeting between the senior rheumatologists and the health psychologists in charge of the interview analysis, all domains were collected, and an affirmative statement was formulated for each domain. This format was preferred over an interrogative one, because the latter is usually perceived as intrusive by patients. The response modality was a Likert scale of six answers ranging from 'absolutely true' to 'completely untrue'.

A complementary study was performed in April 2011 on a series of 12 new patients with RA (different from those who were involved in the previous interviews), who were asked first to read the questionnaire. These 12 patients were asked whether they felt that this questionnaire described a flare, 'their' flare, and did not miss any important features of RA flare. They were also asked to read each item separately, and comment on it, by responding to four questions. (1) Is the item suggestive of a flare? (2) Does the wording need improvement? (3) Would you suggest changes in terms? (4) Which item do you feel to be the most important for describing a flare of RA? 


\section{RESULTS}

\section{Patient perspective}

In total, 102 patients were interviewed, and complete data were available for 99 . Most patients (61\%) reported that a flare usually starts with a feeling of swelling in the joints, and $11 \%$ mentioned frozen joints. An increase in pain was cited by all patients, with various qualifications of pain (very strong, $54 \%$; arduous, $7.1 \%$; shooting, $16.1 \%$; unbearable, $19.6 \%$; excruciating, $7.1 \%$ ) and associated with an increase in daily intake of analgesics (eg, non-steroid anti-inflammatory drugs, steroids) for $82 \%$ of patients. During the flare, $66.6 \%$ of patients declared feeling depressed, $77 \%$ having sleep disturbances, $91 \%$ feeling more tired, and $96 \%$ reporting repercussions on daily activities. Patients reported feeling loss of independence (87.5\%) and emotionally more fragile during the flare (91\%). Only $9 \%$ of the participants reported flu-like symptoms.

From this content analysis, we selected 10 domains to describe RA flare according to the patient perspective. Six answer modalities were proposed for these 10 items, which allowed detection of items over the preceding 3 months (table 1).

\section{Physician perspective}

In the first Delphi round, the rheumatologists proposed 105 items, which were homogenised to 19 items and organised into 14 domains, then used for subsequent rounds. The Delphi process required four additional rounds to obtain converging results in which all domains were accepted by more than $75 \%$ of the respondents. Finally, eight domains were selected, one biological and seven clinical.

\section{Development of the FLARE self-administered questionnaire}

Among the 10 patient-reported domains and the eight physician-reported ones, four were the same: joint swelling, pain, sleep disturbance and intake of analgesics. During the final meeting, the common domains were merged. A domain relative to biological work-up abnormalities - mentioned by the physicians-was eliminated because it did not fit with the framing of a self-administered questionnaire.
All the remaining domains were used to build the questionnaire. For each domain, the group of physicians and health psychologists developed a statement presenting the concept of the domain. The statements were homogeneously formulated and introduced as follows: 'In the last 3 months, or at some time since the last medical consultation, < statement $>$ '. For each statement, the respondent had to indicate agreement by choosing on a Likert scale one of six possible answers from 'absolutely true' to 'completely untrue'. The English version of the FLARE self-reported questionnaire is presented in table 2 , and the original French version in table 3.

\section{Responses to the complementary study}

The hierarchy of responses for the question 'which item do you feel to be one of the most important for describing a flare of RA' was: item 5 (7/12 patients selected it as 'one of the most important'), items $3,4,8,9,10,11,12$ (selected by $6 / 12$ patients), items 1,13 (selected by $5 / 12$ patients), items 2,6 (selected by $4 / 12$ patients), and item 7 (selected by $3 / 12$ patients). In other words, items 8-13 (selected only by the first set of 102 patients) were as often considered as 'the most important' in this complementary study as items 1-7 (selected only by the physicians).

\section{DISCUSSION}

We developed a self-administered tool that aims to detect RA flares between two medical consultations. The FLARE questionnaire should be appropriate for identifying any increase in RA disease activity regardless of its duration (transient or long lasting). However, this tool still needs to be validated, and its ability to ensure a tighter adjustment of treatments to the overall activity of RA between two visits will also need further assessment. In its final version, it should be suitable for clinical research and might be for daily clinical practice.

The concept of flare usually differs according to patient and physician perspectives. Patients focus on subjective changes such as pain, general signs, mood disturbance and the need to seek help. ${ }^{5}$ Physicians are more likely to consider objective changes on which they can base treatment decision-making.

Table 1 Items important to consider in the definition of rheumatoid arthritis flare (new onset or increase in disease) elicited during patient semistructured interviews and the Delphi consensus method for physicians

\begin{tabular}{ll}
\hline Patient perspective & \\
\hline Selected items & Frequency (\%) \\
\hline Joint swelling & 50 \\
Severe or unbearable joint pain & 61 \\
Night awakening by pain & 81 \\
Daily dose of analgesics & 26 \\
Fatigue & 93 \\
Could not 'do a thing' & 18 \\
Increased need for help & 86 \\
Withdrawal, wish to stay alone & 19 \\
Feeling depressed & 74 \\
Irritability & 53
\end{tabular}

\begin{tabular}{ll} 
Physician perspective & \\
\hline & Frequency (\%) \\
\hline Joint swelling & 100 \\
Joint pain level & 100 \\
Night awakening by pain & 92 \\
Daily dose of analgesics & 77 \\
Morning stiffness & 92 \\
Patient global assessment of arthritis & 100 \\
C-reactive protein level or erythrocyte sedimentation rate & 100 \\
Daily dose of steroids & 77
\end{tabular}

Non-selected items

$\begin{array}{ll}\text { Extra-articular manifestations } & 62 \\ \text { Disability, work limitation } & 46 \\ \text { Joint imaging (eg, ultrasound) } & 38 \\ \text { Physician global assessment } & 38 \\ \text { Feeling of an arthritic flare } & \end{array}$

'Non-selected items' refer to items not selected during the last round of the Delphi process in the list devoted to the rheumatologists' perspective, as fewer than $75 \%$ of rheumatologists accepted them in this round $(62 \%, 46 \%, 38 \%)$. Conversely, all attributes identified during the analysis of the semistructured interviews were kept in the patient's list. 
Table 2 The FLARE self-administered questionnaire

Information before scale completion: this questionnaire has been designed to be completed by the patient him/herself or by the physician asking the questions during a consultation In the last 3 months (or at some time since the last consultation) please indicate how true the statements below are for you personally (please tick the number)

\begin{tabular}{|l|l|l|l|l|l|}
\hline 1 - You noticed the appearance or worsening of morning stiffness in joints over several consecutive days & Untrue & Completely untrue \\
\hline Absolutely true & True & Fairly true & Not really true & $\square$ & $\square$ \\
\hline$\square$ & $\square$ & $\square$ & $\square$ & $\square$ & $\square$ \\
\hline
\end{tabular}

2 - You noticed the appearance or worsening of pain in one or several joints over several consecutive days

\begin{tabular}{|l|l|l|l|l|l|}
\hline Absolutely true & True & Fairly true & Not really true & Untrue & Completely untrue \\
\hline$\square$ & $\square$ & $\square$ & $\square$ & $\square$ & $\square$ \\
\hline
\end{tabular}

3 - You noticed the appearance or worsening of swelling in one or several joints over several consecutive days

\begin{tabular}{|l|l|l|l|l|l|}
\hline Absolutely true & True & Fairly true & Not really true & Untrue & Completely untrue \\
\hline$\square$ & $\square$ & $\square$ & $\square$ & $\square$ & $\square$ \\
\hline
\end{tabular}

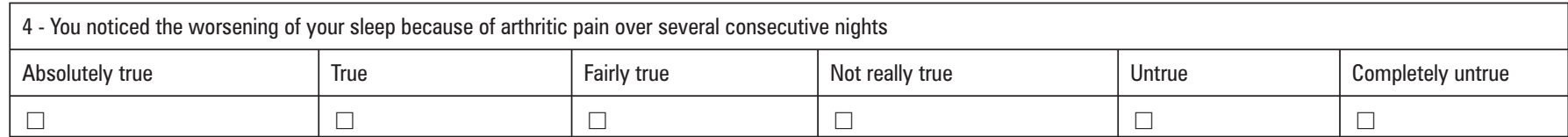

5 - You noticed a marked worsening in your arthritis lasting several consecutive days

\begin{tabular}{|l|l|l|l|l|l|}
\hline Absolutely true & True & Fairly true & Not really true & Untrue & Completely untrue \\
\hline$\square$ & $\square$ & $\square$ & $\square$ & $\square$ & $\square$ \\
\hline
\end{tabular}

6 - You increased your doses of pain killers or anti-inflammatory medication over several consecutive days (If you are not taking any pain killer, select 'Completely untrue')

\begin{tabular}{|l|l|l|l|l|l|}
\hline Absolutely true & True & Fairly true & Not really true & Untrue & Completely untrue \\
\hline$\square$ & $\square$ & $\square$ & $\square$ & $\square$ & $\square$ \\
\hline
\end{tabular}

7 - You increased your daily dose of prednisone for several consecutive days

(If you are not taking prednisone, select 'Completely untrue')

\begin{tabular}{|l|l|l|l|l|l|}
\hline Absolutely true & True & Fairly true & Not really true & Untrue & Completely untrue \\
\hline$\square$ & $\square$ & $\square$ & $\square$ & $\square$ & $\square$ \\
\hline
\end{tabular}

8 - You felt particularly tired for several consecutive days because of your rheumatic disorder

\begin{tabular}{|l|l|l|l|l|l|}
\hline Absolutely true & True & Fairly true & Not really true & Untrue & Completely untrue \\
\hline$\square$ & $\square$ & $\square$ & $\square$ & $\square$ & $\square$ \\
\hline
\end{tabular}

9 - You were so restricted that you have decreased your daily activity over several consecutive days because of your rheumatic disorder

\begin{tabular}{|l|l|l|l|l|l|}
\hline Absolutely true & True & Fairly true & Not really true & Untrue & Completely untrue \\
\hline$\square$ & $\square$ & $\square$ & $\square$ & $\square$ & $\square$ \\
\hline
\end{tabular}

10 - You felt more irritable than usual over several consecutive days because of your rheumatic disorder

\begin{tabular}{|l|l|l|l|l|l|}
\hline Absolutely true & True & Fairly true & Not really true & Untrue & Completely untrue \\
\hline$\square$ & $\square$ & $\square$ & $\square$ & $\square$ & $\square$ \\
\hline
\end{tabular}

\begin{tabular}{|l|l|l|l|l|l|}
\hline $11-$ You felt depressed over several consecutive days because of your rheumatic disorder \\
\hline Absolutely true & True & Fairly true & Not really true & Untrue & Completely untrue \\
\hline$\square$ & $\square$ & $\square$ & $\square$ & $\square$ & $\square$ \\
\hline
\end{tabular}

12 - You felt you wanted to withdraw and be alone over several consecutive days, because of your rheumatic disorder

\begin{tabular}{|l|l|l|l|l|l|}
\hline 12 - You felt you wanted to withdraw and be alone over several consecutive days, because of your rheumatic disorder \\
\hline Absolutely true & True & Fairly true & Not really true & Untrue & Completely untrue \\
\hline$\square$ & $\square$ & $\square$ & $\square$ & $\square$ & $\square$ \\
\hline
\end{tabular}

\begin{tabular}{|l|l|l|l|l|l|}
\hline 13 - You felt an increased need for help over several consecutive days, because of your rheumatic disorder \\
\hline Absolutely true & True & Fairly true & Not really true & Untrue & Completely untrue \\
\hline$\square$ & $\square$ & $\square$ & $\square$ & $\square$ & $\square$ \\
\hline
\end{tabular}

FLARE, Flare Assessment in Rheumatoid Arthritis. 
Table 3 The FLARE self-administered questionnaire in French

Auto-questionnaire FLARE

Information préalable au remplissage du questionnaire: Ce questionnaire a été créé de telle manière qu'il peut soit être rempli par le patient seul, soit par le médecin qui recueille les réponses aux questions posées

Durant les 3 derniers mois (ou depuis la dernière consultation), veuillez indiquer jusqu'à quel point les affirmations ci-dessous sont vraies pour vous (merci d'entourer le chiffre correspondant)

\begin{tabular}{|c|c|c|c|c|c|}
\hline \multicolumn{6}{|c|}{1 - Vous avez constaté l'apparition ou l'aggravation d'un dérouillage matinal articulaire pendant plusieurs jours de suite } \\
\hline Tout à fait vrai & Vrai & Plutôt vrai & Plutôt faux & Faux & Tout à fait faux \\
\hline$\square$ & $\square$ & $\square$ & $\square$ & $\square$ & $\square$ \\
\hline Tout à fait vrai & Vrai & Plutôt vrai & Plutôt faux & Faux & Tout à fait faux \\
\hline$\square$ & $\square$ & $\square$ & $\square$ & $\square$ & $\square$ \\
\hline
\end{tabular}

3 - Vous avez constaté l'apparition ou l'aggravation du gonflement d'une ou plusieurs articulations pendant plusieurs jours de suite

\begin{tabular}{|l|l|l|l|l|l|}
\hline Tout à fait vrai & Vrai & Plutôt vrai & Plutôt faux & Faux & Tout à fait faux \\
\hline$\square$ & $\square$ & $\square$ & $\square$ & $\square$ & $\square$ \\
\hline
\end{tabular}

4 - Vous avez constaté l'apparition ou l'aggravation de réveils plusieurs nuits de suite à cause des douleurs de votre polyarthrite

\begin{tabular}{|l|l|l|l|l|l|}
\hline Tout à fait vrai & Vrai & Plutôt vrai & Plutôt faux & Faux & Tout à fait faux \\
\hline$\square$ & $\square$ & $\square$ & $\square$ & $\square$ & $\square$ \\
\hline
\end{tabular}

\begin{tabular}{|l|l|l|l|l|l|}
\hline 5 - Vous pensez que votre polyarthrite s'est aggravée de façon nette pendant plusieurs jours de suite & Faux \\
\hline Tout à fait vrai & Vrai & Plutôt vrai & Plutôt faux & Tout à fait faux \\
\hline$\square$ & $\square$ & $\square$ & $\square$ & $\square$ & $\square$ \\
\hline
\end{tabular}

6 - Vous avez augmenté vos prises de médicaments contre la douleur (antalgiques ou anti-inflammatoires) pendant plusieurs jours de suite (Si vous ne prenez aucun médicament contre la douleur, cochez « 0 »)

\begin{tabular}{|l|l|l|l|l|l|}
\hline Tout à fait vrai & Vrai & Plutôt vrai & Plutôt faux & Faux & Tout à fait faux \\
\hline$\square$ & $\square$ & $\square$ & $\square$ & $\square$ & $\square$ \\
\hline
\end{tabular}

7 - Vous avez augmenté vos prises de cortisone pendant plusieurs jours de suite du fait de votre polyarthrite (Si vous ne prenez pas de cortisone, cochez « 0 »)

\begin{tabular}{|l|l|l|l|l|l|}
\hline Tout à fait vrai & Vrai & Plutôt vrai & Plutôt faux & Faux & Tout à fait faux \\
\hline$\square$ & $\square$ & $\square$ & $\square$ & $\square$ & $\square$ \\
\hline
\end{tabular}

8 - Vous vous êtes senti(e) très fatigué(e) pendant plusieurs jours de suite du fait de votre polyarthrite

\begin{tabular}{|l|l|l|l|l|l|}
\hline Tout à fait vrai & Vrai & Plutôt vrai & Plutôt faux & Faux & Tout à fait faux \\
\hline$\square$ & $\square$ & $\square$ & $\square$ & $\square$ & $\square$ \\
\hline
\end{tabular}

\begin{tabular}{|l|l|l|l|l|l|}
\hline 9 - Vous avez été tellement limité(e) que vous ne pouviez « plus rien faire » pendant plusieurs jours de suite du fait de votre polyarthrite \\
\hline Tout à fait vrai & Vrai & Plutôt vrai & Plutôt faux & Faux & Tout à fait faux \\
\hline$\square$ & $\square$ & $\square$ & $\square$ & $\square$ & $\square$ \\
\hline
\end{tabular}

\begin{tabular}{|l|l|l|l|l|l|}
\hline 10 - Vous vous êtes senti plus irritable pendant plusieurs jours de suite du fait de votre polyarthrite \\
\hline Tout à fait vrai & Vrai & Plutôt vrai & Plutôt faux & Faux & Tout à fait faux \\
\hline$\square$ & $\square$ & $\square$ & $\square$ & $\square$ & $\square$ \\
\hline
\end{tabular}

\begin{tabular}{|c|c|c|c|c|c|}
\hline \multicolumn{6}{|c|}{11 - Vous avez ressenti une baisse de moral pendant plusieurs jours de suite du fait de votre polyarthrite } \\
\hline Tout à fait vrai & Vrai & Plutôt vrai & Plutôt faux & Faux & Tout à fait faux \\
\hline$\square$ & $\square$ & $\square$ & $\square$ & $\square$ & $\square$ \\
\hline
\end{tabular}

12 - Vous avez eu envie de vous replier sur vous-même ou de vous isoler pendant plusieurs jours de suite du fait de votre polyarthrite

\begin{tabular}{|l|l|l|l|l|l|}
\hline $12-$ Vous avez eu envie de vous replier sur vous-même ou de vous isoler pendant plusieurs jours de suite du fait de votre polyarthrite \\
\hline Tout à fait vrai & Vrai & Plutôt vrai & Plutôt faux & Faux & Tout à fait faux \\
\hline$\square$ & $\square$ & $\square$ & $\square$ & $\square$ & $\square$ \\
\hline
\end{tabular}

13 - Vous avez ressenti un plus grand besoin d'aide pendant plusieurs jours de suite du fait de votre polyarthrite

\begin{tabular}{|l|l|l|l|l|l|}
\hline Tout à fait vrai & Vrai & Plutôt vrai & Plutôt faux & Faux & Tout à fait faux \\
\hline$\square$ & $\square$ & $\square$ & $\square$ & $\square$ & $\square$ \\
\hline FLARE, Flare Assessment in Rheumatoid Arthritis.
\end{tabular}


Different scientific organisations such as the OMERACT group, the American College of Rheumatology or the European League Against Rheumatism have recommended considering both perspectives because they are usually not redundant, ${ }^{16} 17$ but often complement each other. This recommendation was confirmed in our work because only four of the 10 patient-proposed items and eight physician-proposed items were common to both types of respondent: joint swelling, pain, sleep disturbance and intake of analgesics.

The FLARE self-administered questionnaire is also complementary to the rheumatologist examination (eg, joint counts or disease activity score using 28 joint counts) because it collects information about disease activity that occurred between two consultations and may be absent at the time of the visit to the physician.

The FLARE instrument may also be useful for patients to selfdetect a flare and subsequently ask for a prompt appointment, although thresholds could vary according to the patient. Indeed, Hewlett et al ${ }^{18}$ showed in a 6 -year prospective trial that patients with RA who initiated their reviews through direct access were clinically and psychologically at least as well as patients with traditional reviews initiated by physicians. Moreover, the former patients requested fewer appointments (more than onethird fewer medical appointments), which reduced the overall use of restricted healthcare resources. ${ }^{18}$

Many chronic diseases can be punctuated by exacerbations. These exacerbations are not always captured by activity scores, which are obtained only during scheduled visits and require physician assessment and/or blood sampling (erythrocyte sedimentation rate or C-reactive protein measurement). Fluctuations of sufficient duration could affect radiographic and functional outcome. 'Flare' is commonly used by patients and clinicians to describe a worsening of symptoms and is encountered in various autoimmune diseases such as atopic dermatitis, ${ }^{19}$ ankylosing spondylitis, ${ }^{9}$ juvenile arthritis, ${ }^{20} 21$ lupus ${ }^{22} 23$ and gout. ${ }^{24}$ Numerous efforts have aimed to define validated end points for improvement in RA in RCTs or in daily practice, but no thresholds have been set to define a significant worsening of disease activity. ${ }^{5}$ Accordingly, although 'RA flare' is conceptually recognised, evidence is limited and a consensual definition is lacking. ${ }^{57}$ This absence is not restricted to RA, because a definition of gout flare has not yet been validated, even though gout has been described since antiquity ${ }^{24}$ and experienced by millions of patients; nevertheless, patients are treated and cured.

The OMERACT group defined flare in RA as 'a cluster of symptoms of sufficient duration and intensity that cannot be self-managed by the patient and require initiation, change or increase in therapy'. 57 This definition does not explicitly consider the possibility of a return to disease baseline ('end of flare'), because the authors sought to build a tool for RCTs first (to recognise as soon as possible loss of efficacy of treatments or quantitatively characterise reasons for study withdrawal on the basis of loss, or lack, of efficacy), ${ }^{5}$ although the ultimate goal is also to enhance clinical care. ${ }^{6}$ Our work seems to be complementary to the OMERACT initiative, which involves some of the STPR members. Although based on a slightly different concept of flare and different methodology, the preliminary results of the OMERACT project and our results are consistent.

At least six issues remain unresolved. First, no threshold of disease worsening has been established to define a flare, which may be explained by the perception of the severity of flare differing between patients, and for a single patient from time to time. This variation in severity of flare prompted us to propose a Likert scale with six possible answers for each question, which offers the opportunity to express the final result of the 'flare instrument' quantitatively (as a score) or qualitatively (flare or no flare, according to a threshold for flare). This format has still to be defined and tested against an anchor assessment of RA activity by another score with previously established thresholds of significance, such as routine assessment of patient index data (RAPID)-3, which can be longitudinally fulfilled by the patients on a home-made basis. ${ }^{25}$

Second, the duration of symptom exacerbation remains to be clarified. Our patient interviews revealed significant variations in the defined duration of flare, ranging from a few days to a couple of weeks or months. These discrepancies have been observed in other diseases. ${ }^{10} 1921$ The scientific community has identified an area for research, because definition of a 'sufficient duration' (to lead to structural damage) may be as important as the definition of flare itself. While waiting for such a definition, we chose to capture any flare the patient remembered, regardless of its duration or recurrence.

The third issue relates to the ability of patients to correctly remember with sufficient accuracy all events occurring between two clinic visits. We chose a period of 3 months because it is the delay most often considered optimal in RA care. A longer period could be subjected to a stronger memory bias. Indeed, previous studies have shown that retrospective evaluation of pain within the past week or month already leads to a slight overestimation of pain actually experienced during those short periods. ${ }^{26} 27$ However, patients with RA seemed to more correctly recall and report flare frequency and pain intensity than other painful conditions. ${ }^{26} 28-30$ However, problems could arise with features other than pain, especially general features (flu-like symptoms), which are probably forgotten even more quickly than worsening of pain. This situation may be illustrated by only a few of our patients focusing on this aspect, although it has been emphasised in group meetings of patients. ${ }^{510}$

The fourth limitation (inherent to the choice of a self-administered tool also allowing the detection of flares between two visits) was the need to discard both biological results and physicians' global assessment from the list of items first selected by physicians during the Delphi process.

The fifth issue is that this questionnaire has only been developed in the French language, with the input of French physicians and patients. Trans-cultural differences in the meaning of 'flare' might have led to the selection of different items or wordings in other languages or settings.

Last, whether the patients perceive the questions as only related to their arthritis/condition, or as a result of other outside forces, has not been tested.

This tool needs to be validated in a prospective trial of patients with three main objectives: (1) the validity of the tool ${ }^{31}$ (internal validity, measured with a multiple factorial analysis, and a Rasch model, the external validity being evaluated by correlation scores with the RAPID and the rheumatoid arthritis impact of disease score); (2) the reliability and responsiveness of the tool (reproducibility, sensitivity to change, and effect of the tool on decision) $)^{31}$; and (3) the feasibility of using this score, ${ }^{31}$ even in daily practice. Then, the predictive capacity of the tool must be evaluated.

Acknowledgments We thank the health professionals who performed patient interviews: S Laudicini, Aulnay sous Bois; E Jeannet, Besançon; S Asquoet, Brest; C Chevalier, Dijon; B Endewelt, Grenoble; L Conti, Marseille; S Marchal, Montpellier; F Brun, Nantes; V Demaie, Paris-Bichat; I Henry, Paris-Pitié; C Guilleux, Poitiers; S Chambellan, Rouen; M H Cerato, Toulouse. We also thank Professor I Chary-Valckenaere 
for facilitating patient interviews during the pilot phase of the study, and L Smales for copyediting.

Funding The research project was funded by an unrestricted grant from SanofiAventis France. The firm had no access to the data and was not involved in the study design or conduct or data analysis.

Competing interests None.

Ethics approval This study was conducted with the approval of the Université Henri Poincaré - Nancy 1, Université Paul Verlaine Metz.

Provenance and peer review Not commissioned; externally peer reviewed.

Author affiliations ${ }^{1}$ INSERM ERI 7 (EA 3822) Centre Hospitalo-Universitaire de Nantes, Hôtel-Dieu, Service de Rhumatologie, Nantes, France

${ }^{2}$ Centre hospitalier d'Aulnay sous Bois, Service de Rhumatologie, Aulnay sous Bois, France

${ }^{3} \mathrm{CHU}$ Lapeyronie, Département de Rhumatologie, Montpellier cedex, France

4Université Henri Poincaré - Nancy 1, France

5 Université Paul Verlaine Metz, Metz, France

${ }^{6}$ Université Paris Descartes, EA 4360 APEMAC, Metz, France

7Hôpital Larrey, Toulouse cedex, INSERM U558, Toulouse, France

${ }^{8}$ Univ P Sabatier, Toulouse, France

${ }^{9}$ Hôpital Sud A. Michallon Grenoble cedex, France

${ }^{10}$ Rouen University Hospital Department of Rheumatology, \& Inserm U905 (IFRMP 23), University of Rouen, France

${ }^{11}$ Centre Hospitalo-Universitaire du Dijon, Hôpital du Bocage, Service de

Rhumatologie, Dijon, France

12Université Denis Diderot - Paris, France

${ }^{13}$ UFR de Médecine, Paris, F-75010, France

${ }^{14}$ AP-HP, GH Bichat, Service de Rhumatologie, Paris, France

${ }^{15} \mathrm{CHU}$ Sainte-Marguerite, Department of Rheumatology, Marseille cedex, France

${ }^{16}$ Centre Hospitalo-Universitaire de Brest, Hôpital de la Cavale Blanche, Service de Rhumatologie, Brest, France

${ }^{17} \mathrm{CHU}$ de Poitiers, 86021 Poitiers cedex, France

${ }^{18}$ Université de Franche-Comté EA4266 - Agents pathogènes et Inflammation, and Centre, Besançon, France

${ }^{19}$ Hospitalo-Universitaire de Besançon, Hôpital Jean Minjoz, Service de Rhumatologie, Besançon, France

20Université Pierre et Marie Curie - Paris, France

${ }^{21}$ AP-HP, GH Pitié Salpêtrière, Service de Rhumatologie, Paris, France

22INSERM CIC-EC, Nancy University Hospital, Nancy, France

\section{REFERENCES}

1. Kremer JM, Rynes RI, Bartholomew LE. Severe flare of rheumatoid arthritis after discontinuation of long-term methotrexate therapy. Double-blind study. Am J Med 1987; 82:781-6

2. Maravic M, Bergé $\mathbf{C}$, Daurès JP, et al. Practices for managing a flare of long-standing rheumatoid arthritis: survey among French rheumatologists. Clin Exp Rheumatol 2005;23:36-42.

3. Fransen J, Häuselmann H, Michel BA, et al. Responsiveness of the self-assessed rheumatoid arthritis disease activity index to a flare of disease activity. Arthritis Rheum 2001;:44:53-60.

4. Caldwell JR, Furst DE, Smith AL, et al. Flare during drug withdrawal as a method to support efficacy in rheumatoid arthritis: amiprilose hydrochloride as an example in a double blind, randomized study. J Rheumatol 1998;25:30-5.

5. Bingham $\mathbf{C O} 3^{\text {rd }}$, Pohl C, Woodworth TG, et al. Developing a standardized definition for disease "flare" in rheumatoid arthritis (OMERACT 9 Special Interest Group) J Rheumatol 2009;36:2335-41.

6. Bingham C0.3rd, Pohl C, Alten R, et al. "Flare" and disease worsening in rheumatoid arthritis: time for a definition. Int J Adv Rheumatol 2009:7:85-91.

7. Yazici Y, Erkan D, Kulman I, et al. Decreased flares of rheumatoid arthritis during the first year of etanercept treatment: further evidence of clinical effectiveness in the "real world". Ann Rheum Dis 2002:61:638-40.
8. Welsing PM, Landewé RB, van Riel PL, et al. The relationship between disease activity and radiologic progression in patients with rheumatoid arthritis: a longitudinal analysis. Arthritis Rheum 2004:50:2082-93.

9. Berthelot JM, Blanchais A, Marhadour T, et al. Fluctuations in disease activity scores for inflammatory joint disease in clinical practice: do we need a solution? Joint Bone Spine 2009;76:126-8.

10. Brophy S, Calin A. Definition of disease flare in ankylosing spondylitis: the patients perspective. J Rheumatol 2002;29:954-8.

11. Leeb BF, Sautner J, Leeb BA, et al. Lack of agreement between patients' and physicians' perspectives of rheumatoid arthritis disease activity changes. Scand J Rheumatol 2006;35:441-6.

12. Kirwan JR, Hewlett SE, Heiberg T, et al. Incorporating the patient perspective into outcome assessment in rheumatoid arthritis-progress at OMERACT 7. J Rheumatol 2005;32:2250-6.

13. Meyer 0, de Bandt M, Berthelot JM, et al. Clinical practice format for choosing a second-line disease modifying anti-rheumatic drug in early rheumatoid arthritis after failure of 6 months' first-line DMARD therapy. Joint Bone Spine 2007;74:73-8.

14. Le Loët X, Berthelot JM, Cantagrel A, et al. Clinical practice decision tree for the choice of the first disease modifying antirheumatic drug for very early rheumatoid arthritis: a 2004 proposal of the French Society of Rheumatology. Ann Rheum Dis 2006;65:45-50.

15. de Bandt M, Fautrel B, Maillefert JF, et al. Determining a low disease activity threshold for decision to maintain disease-modifying antirheumatic drug treatment unchanged in rheumatoid arthritis patients. Arthritis Res Ther 2009;11:R157.

16. Sanderson T, Morris M, Calnan M, et al. Patient perspective of measuring treatment efficacy: the rheumatoid arthritis patient priorities for pharmacologic interventions outcomes. Arthritis Care Res (Hoboken) 2010;62:647-56.

17. de Wit MP, Berlo SE, Aanerud GJ, et al. European League Against Rheumatism recommendations for the inclusion of patient representatives in scientific projects. Ann Rheum Dis 2011:70:722-6.

18. Hewlett SE, Haynes J, Shepstone L, et al. Rheumatoid arthritis patients cannot accurately report signs of inflammatory activity. Br J Rheumatol 1995;34:547-53.

19. Langan SM, Thomas KS, Williams HC. What is meant by a "flare" in atopic dermatitis? A systematic review and proposal. Arch Dermatol 2006;142:1190-6.

20. Ringold S, Wallace CA. Measuring clinical response and remission in juvenile idiopathic arthritis. Curr Opin Rheumatol 2007:19:471-6.

21. Brunner HI, Lovell DJ, Finck BK, et al. Preliminary definition of disease flare in juvenile rheumatoid arthritis. J Rheumatol 2002;29:1058-64.

22. FitzGerald JD, Grossman JM. Validity and reliability of retrospective assessment of disease activity and flare in observational cohorts of lupus patients. Lupus 1999;8:638-44.

23. Petri M, Buyon J, Kim M. Classification and definition of major flares in SLE clinical trials. Lupus 1999;8:685-91.

24. Taylor WJ, Shewchuk R, Saag KG, et al. Toward a valid definition of gout flare: results of consensus exercises using Delphi methodology and cognitive mapping. Arthritis Rheum 2009;61:535-43.

25. Blanchais A, Berthelot JM, Fontenoy AM, et al. Weekly home self-assessment of RAPID-4/3 scores in rheumatoid arthritis: a 6-month study in 26 patients. Joint Bone Spine 2010;77:582-7.

26. McKenzie JA, Cutrer FM. How well do headache patients remember? A comparison of self-report measures of headache frequency and severity in patients with migraine. Headache 2009:49:669-72.

27. Broderick JE, Schwartz JE, Vikingstad G, et al. The accuracy of pain and fatigue items across different reporting periods. Pain 2008;139:146-57.

28. Jorge LL, Gerard C, Revel M. Evidences of memory dysfunction and maladaptive coping in chronic low back pain and rheumatoid arthritis patients: challenges for rehabilitation. Eur J Phys Rehabil Med 2009;45:469-77.

29. Lefebvre JC, Keefe FJ. Memory for pain: the relationship of pain catastrophizing to the recall of daily rheumatoid arthritis pain. Clin J Pain 2002;18:56-63.

30. Schwegler K, Ettlin D, Buser I, et al. Cortisol reduces recall of explicit contextual pain memory in healthy young men. Psychoneuroendocrinology 2010:35:1270-3.

31. Boers $\mathbf{M}$, Brooks $P$, Strand CV, et al. The OMERACT filter for outcome measures in rheumatology. J Rheumatol 1998;25:198-9. 